in these cases of delayed death after an anæsthetic is the presence of acetone in the urine, and associated with this condition of the urine one of the most striking symptoms is vomiting. Acetonuria is, it is needless to say, a marked feature of the cases known as "recurrent vomiting" in children. Severe cases of this affection are not very often met with, but milder examples, which Dr. Guthrie speaks of under the popular name of "bilious attacks," are common. It does not seem to me, however, that a fatty liver is necessarily associated with acetonuria and recurrent vomiting in children. Fatal instances of this affection are rare but it has fallen to my lot to perform the necropsy on a case where death occurred. The urine contained acetone but although I did not examine the liver microscopically it was certainly not what could be called a fatty liver. It was not in any degree enlarged and presented no abnormal appearances to the naked eye. But even if it be allowed that microscopical examination may have shown in this case some excess of fat in the liver it seems to me to be difficult to believe that fat in the liver can have anything to do with a disease which lasts for years, as does recurrent vomiting. Not only does it seem to me to be very doubtful whether a fatty liver can play a part in the causation of acctonuria associated with recurrent vomiting, but the question arises whether it $i_{3}$ an important factor in the causation of acetonuria, vomiting, and death after the administration of an anæsthetic. That a well-marked fatty liver may be present it is impossible to deny. I have already mentioned a case that has come under my own notice but before great stress is laid upon the presence of a fatty liver one must be sure that in virtually every fatal case the amount of fat in the liver is really definitely above what is commonly present. I am, Sirs, yours faithfully,

Sept. 3rd, 1905. TheODORE Fisher.

\section{THE SPA TREATMENT OF CIRCULATORY DISORDERS.}

\section{To the Editors of THE LANCET.}

SiRS,-In his paper on the Spa Treatment of Circulatory Disorders in THE LANCET of August 5th, Dr. L. Williams gives many valuable hints as to the pathology and treatment of these affections but bases his verdict on Nauheim in special on wrong views regarding its climate, the physiological action of its springs, and the methods of treatment nsed there. I hope to conduce to a correct understanding of the facts by the following statements.

1. Climate.-From the end of May till the end of June and September again are the finest times of the season, which lasts from May 1st to Oct. 1st. During these months the temperatare is equable, neither excessively hot nor disagreeably c jol. September, more especially, is by no means rainy, as Dr. Williams believes, but, on the contrary, is noted for the constancy of fine weather which, in conjunction with the bracing qualities of the air peculiar in these latitudes at the end of summer and beginning of autumn, perhaps renders this month climatically the most invigorating one of the whole year. Iuly and August have hot days here as everywhere in these latitudes but the proximity of the Taunus hills and the prevalence of easterly winds render the nights agreeably cool even then, and rarely does a spell of hot weather last more than a few days without being relieved by a change of weather; these "sudden and decided changes" are a distinct advantage then at this time of the year, whilst at others they are no more pronounced than anywhere else.

2. Physiological aotion. - The theory that the carbonic acid brine baths chiefly act by stimulating the heart to more energetic contractions and increasing blood pressure is antiquated and has been replaced by the theory that the action is chiefly due to lessening of peripheral resistances in the vessels. The fact is that in high blood pressure this is generally lowered by the baths, whilst only cases of abnormally low pressure and loss of arterial tension experience an increase of blood pressure and of vascular tension through the baths. To explain this monistically I have advanced $t$ te following theory: As is known, the action of the baths is ewofold-(1) local, consisting in dilatation of the capillaries of the skin; this means decrease of peripheral resistance; (2) reflex by stimulation of the cutaneous sensory nerves, the stimulus acting on the centres of the vasc-notor and pneumogastric nerves; this brings about increase of arterial tension with consequent rise of blood pressure and slowing of the heart's action (stimulation of the vagus). In cardiac disorders, however, the diminished velocity of the current of the blood leads to an accumulation of carbonic acid gas in the blood; this, we know from physiology, stimulates the vaso-motor centres in the medulla and brings about arterio-spasm; hence in so many cardiac cases we meet with an excessively high bliod pressure. Further, we know from physiology that the velocity of the circulation is the greater in a given section of the vascular system the greater the propulsive power at the beginning of the said section, and the less the resistance at its end be; the capillary dilatation reduces this $r$ sistance, thus accelerating the circulation. The acceleration leads to the elimination of the accumulated carbonic acid; this being eliminated the abnormal stimulus on the vaso-motor centre is abolished and consequently blood pressure falls in these cases. The stimulating action of the baths on the vaso-motor system therefore only comes into action so far as to increase an abnormally low tonus towards normal, but not beyond this. And practically this theory is corroborated by our seeing good results from the Nauheim baths in cases of high blood pressure as well as in cases of low blood pressure. The chief effect is to relieve the heart (1) by capillary dilatation in all cases; and (2) by removing arterial spasm in cases where it exists. There is no physiological basis for assuming that the heart is stimulated itself actively to more vigorous contractions. Even the re-establishment of lost arterial tone would not act as a stimuius but as a relief to the heart, because in normal tone the elasticity of the arterial walls constitutes an important driving power and thus the vessels resume their share in propelling the blood which during the stage of lost tension had devolved upon the heart. Only the temperature, therefore, in cool baths throws an initial strain upon the heart and stimulates it to stronger contractions by bringing about contraction of the cutaneous capillaries; but this we entirely command by regulating the temperature at will. Stimulation of the vagus reduces frequency and force of the systoles; that of the accelerans cordis increases both. Both centres can be stimulated through reflex from sensitive nerves; but if both be stimulated simultaneously the action of the vagus prevails. Digitalis causes slower and stranger beats; this latter, therefore can only be due to direct action on the intra-cardiao centres, which is all the more probable, as we know that these are the predominating factors in regulating the heart's action. Such action on the cardiac muscle, however, can onls be possible either by a chemical substance contained in the blood (as is the case with digitalis) or perhaps by electrical stimulation, but not by a stimulus only applied to the surface of the body.

3. "THE Nuheim method."-Baths and exercises, it is true, were originally the only method known at Nauheim of treating cardiac disease. But "tempora mutantur nos et mutamur in illis." There are upwards of 50 physicians now practising at Nauheim, and it would not seem quite illogical to conclude that some of them had the capacity of treating patients on their own lines and of evolving original methods other than those exclusively in vozue formerly. The action of hydro-electrical biths on the circulation was established beyond all doubt as far back as 1883 by Eulenburg by exxot research and since then by others. I may say that my own recent investig ations have led, in conjunction with the light thrown on the subject by former work, preliminarily at least, to an exact definition of the action of baths with the faradic or sinusoidal alternating current on the circulation. Without any doubt they have the following influences : (1) stimulation of the cutaneous sensory nerves with effect on arterial tone (2) acceleration of the circulation by rhythmic contractions of the systemic muscles; (3) potent effects on metabolism and (4) a beneficial effect on the general nervous system. Busides these, the baths have possibly a direct action on the vessels and the heart, as they undoubtedly have on other internal organs (intestines, nterus, and bladder).

It would go beyond the scope of a letter to adduce all the physiological facts and practical experiences whish help to show that a combination of hydro-electrical methods with the Nauheim baths is the best physical treatment for circulatory disorders at the present day. but as this combination took its origin at Nauheim I protest against the "baths and exercises" henceforth being called the Nauheim method unless some qualifying words be added. With regard to the exercises, I am, with Professor A. Hoffmann, of 
opinion that in combination with the baths they are generally contra-indicated.

A word about the Nauheim treatment at other places. There is, of course, no doubt about the possibility of it, but the fact that many different spas on the continent, as well as in England, are making energetic endeavours to gain a reputation in these methods goes to prove the efficacy of them if judiciously applied. It should not be forgotten that the different qualities of the Nauheim waters and the balneological technique are necessary to insure the effects. Physical treatment of cardiac disease, whether by mineral baths, by exercises, or by hydro-electrotherapy, or by any combination of these, is, I quite agree with $\mathrm{Dr}$. Williams, not followed by miraculous results, and is in general only indicated in initial stages.

I am, Sirs, yours faithfully,

PaUl C. Franze, M.D.

The Electrological and Radiological Institute, Bad Naubeim

(Germany), August 29th, 1905

\section{RHEUMATISM AND CLIMATE: A QUERY.} To the Editors of THE LANCET.

SIRS,-I shall be grateful if any of your readers will kindly help me with advice. I have been engaged in wide and wild country practice for the last 14 years and have lately suffered more or less from rheumatism and have also been laid up with lumbago and sciatica. The least wetting or even a long tiring day causes slight recurrence of the trouble. I am at present in a damp climate with clay subsoil in the North of England and am afraid I shall have to make a change. For various reasons I require a bracing place and am fond of seaside or health resort practice. I am middle aged. I shall be very glad of suggestions as to the most suitable districts in which to look for a practice where I may have reasonable hope of escaping an insidious foe and at the same time making a living.

I am, Sirs, yours faithfully,

August 29th, 1905. Practitioner.

\section{THE METROPOLITAN ASYLUMS BOARD AND ITS ASSISTANT MEDICAL OFFICERS. \\ To the Editors of THE LANCET.}

SiRS,-We thank Mr. Scovell for his prompt reply to our letter which appeared in THE LANCET of August 26th and are pleased to note that he considered the question one of sufficient importance to occupy the early attention of the Board. From the opinions which he has expressed we are forced to believe that the Board can neither be fully acquainted with the position of its medical officers nor with the working of the rules by which its institutions are governed. We trust that a thorough inquiry will place these matters in a true light, and until such inquiry has been made the object of our resigning will not have been attained and the position of the assistant medical officers under the Metropolitan Asylums Board will continue to be an extremely unsatisfactory one.

We are, Sirs, yours faithfully,

FraAcIS R. BARWELL. GERARD A. HERKLOTS

Darenth Asylum, Dartford, Kent, H. P. KEnNARD. Sept. 5th, 1905.

New Hospital for the Royal Cornwall SaIloRs' Home at Falmouth. - A few years ago Sir Joseph Fayrer and other members of the medical profession urged on the subscribers of the Royal Cornwall Sailors' Home at Falmouth the necessity of providing a new hospital for that institution. The old building has been in existence about 50 years and it was quite impossible to bring it up to modern requirements. It was consequently decided to erect a new hospital and subscriptions were invited for that purpose. On August 24th Vice-Admiral Sir Lewis Beaumont, commanding Plymouth naval station, laid the foundation stone of the new building in the presence of a large assembly. The hospital will stand in a large garden and will consist of a men's ward for six beds, with two small wards for one bed and two beds respectively. The building will also contain an operating theatre, convalescent ward, nurses' rooms, and the usual offices. The estimated cost is $£ 2500$, of which about $£ 1300$ are still rcquired.

\section{THE SALE OR PURCHASE OF A MEDICAL PRACTICE.}

(From a legal Contributor.)

ALTHOUGH in the majority of instances the sale or purchase of a medical practice is a plain and straightforward transaction, cases sometimes occur which tend to put the young practitioner who is unfamiliar with the ways of the world upon his guard. Moreover, even in cases where everything is fair and above board, one who is unaccustomed to the perusal of legal documents may set his hand to some deed of which he does not understand the true meaning. In these circumstances it is apprehended that our readers may value a few notes upon the subject of agreements for the sale and purchase of a medical practice.

Advantages of an agreement in nriting.-If a practice is to be sold the terms of the sale should be reduced into writing and the agreement executed with the least possible delay. In the case of May $v$. Thomson ((1882) $20 \mathrm{Ch} . \mathrm{D} .705)$, the plaintiff, who wished to sell a medical practice with the lease of the house where it was carried on, placed it on the books of a medical agent. This led to negotiations with the defendant. The premiums asked for the practice and for the lease were stated in a letter from the agent to the defendant, but no time for completing the purchase was mentioned. The defendant replied in a letter to the agent accepting the terms offered and adding that he should be ready to pay the deposit money "on receipt of corrected agreement," and at the same time he wrote to the plaintiff personally, also accepting the terms offered and adding-"I shall trust you to give me the best introduction you can during three months and afterwards if necessary." The plaintiff replied thanking the defendant for acceding to his terms and saying that "it would be his aim as well as his duty to give him an effectual introduction to his patients." A formal agreement was drawn up and never signed, and after some turther correspondence the defendant refused to complete the purchase. Upon an action being brought by the rendor to obtain an order for specific pertormance, the Court of Appeal held that inasmuch as the time for the commencement of the purchase was left uncertain and the stipulation as to three months' introduction was not agreed to, and as the parties contemplated a formal agreement, there was no binding contract between the parties and the action was dismissed.

Perhaps the most satisfactory method of explaining the incidents of a regular transfer of a medical practice is to set out the clauses of a form of agreement which may be signed by the vendor and purchaser, adding such explanatory notes as appear to be necessary. Certain observations of a general nature may first be made.

Ascertanment of the price.-The all-important question, What price is to be paid? must first be satisfactorily determined. I he vendor will naturally seek to enhance the value of the practice while the purchaser will seek to decry it, and the basis of agreementwill probably be the books which have been kept by the vendor. Both vendor and purchaser should exercise the utmost cantion in the use of these books; the vendor because if it should transpire that the books are in any way misleading, or that there has been any suppressio veri in connexion with them, unpleasant consequences may follow, and the purchaser because books of account though honestly and accurately kept may nevertheless mislead a person who does not properly understand them.

Let us take for the sake of illustration an extreme case. Suppose the vendor were to produce books which showed gross receipts of $£ 1000$ a year for two or three years and the purchaser, relying upon the books, gave a sum of $\$ 2000$ for the practice and afterwards discovered that the books had been "faked" for the purpose of enhancing the apparent value of the practice. In such a case the whole transaction might be set aside on the ground of fraud. Where, however, the books are honestly kept and the purchaser has been content to $r$ ly upon the figures contained in them in arriving at the conclusion that a fair price has been asked, he cannot be heard to complain if he is disappointed with the takings of the practice. For instance, supposing a large part of the takings which were entered in the books were derived from two or three wealthy patients. Suppose these patients had left the district before the sale of the transfer. It is an open question whether the vendor should have disclosed this 